Research Paper

\title{
Hepatotoxicity in Advanced Lung Adenocarcinoma: A Retrospective Study of 2108 Cases
}

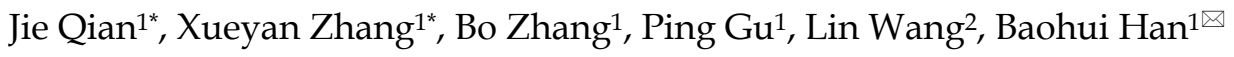 \\ 1. Department of Pulmonary Medicine, Shanghai Chest Hospital, Shanghai Jiao Tong University, Shanghai, China \\ 2. Department of Laboratory Medicine, Shanghai Chest Hospital, Shanghai Jiao Tong University, Shanghai, China \\ * Authors contributed equally
}

$\square$ Corresponding author: Baohui Han, PhD., MD., Department of Pulmonary Medicine, Shanghai Chest Hospital, Shanghai Jiao Tong University, 241\# West Huaihai Rd, Shanghai 230030, China. Tel.: +86 2162821990 ext.1421; Fax: +86 21 32260806; E-mail address: 18930858216@163.com

(c) Ivyspring International Publisher. This is an open access article distributed under the terms of the Creative Commons Attribution (CC BY-NC) license (https://creativecommons.org/licenses/by-nc/4.0/). See http://ivyspring.com/terms for full terms and conditions.

Received: 2017.12.06; Accepted: 2018.02.06; Published: 2018.04.12

\begin{abstract}
The study aimed to identify the risk factors and frequency of hepatotoxicity in patients with advanced lung adenocarcinoma. Liver function tests were documented in 2108 patients with advanced (IIIB/IV) lung adenocarcinoma at a single institution who received first line platinum-based doublet chemotherapy. Hepatotoxicity was graded according to the Common Terminology Criteria for Adverse Events (CTCAE), version 4.0. Risk factors for hepatotoxicity were assessed using logistic regression analysis. Differences in hepatotoxicity between pemetrexed and non-pemetrexed regimens were evaluated after propensity score matching. After accounting for hepatic dysfunction during the first-line treatment, 892 patients receiving beyond first-line treatment were included in the subsequent analyses. Hepatotoxicity in beyond first-line treatment was compared between patients having epidermal growth factor receptor-tyrosine kinase inhibitors (EGFR-TKIs) and chemotherapy alone. In the first-line analysis, 316 (15.0\%) patients developed liver dysfunction. Younger age (Odds Ratio [OR] 2.398, 95\% Confidence Interval [95\% Cl] 1.755-3.275), pretreatment liver impairment (OR 2.285, 95\% Cl 1.622-3.220), and pemetrexed-contained chemotherapy (OR 1.835, $95 \% \mathrm{Cl} 1.408-2.393)$ were risk factors of hepatotoxicity (all $\mathrm{P}<0.001$ ). Significant differences were observed for patients with all grades of hepatotoxicity while no differences were found concerning grade $3 / 4$ hepatotoxicity between 844 pemetrexed and 844 non-pemetrexed regimen matched cases $(P<0.0001$ and $P=0.4220$, respectively). After first-line treatment, the presence of hepatitis virus (OR 2.905, 95\% Cl 1.487-5.675; $P=0.002$ ) and TKI therapy (OR 2.621, 95\% Cl 1.809-3.798; $\mathrm{P}<0.001$ ) were additionally associated with increased hepatotoxicity. Patients with advanced lung adenocarcinoma with younger age, pretreatment liver injury, and presence of hepatitis virus were at high risk for hepatotoxicity following chemotherapy. Pemetrexed-contained chemotherapy and TKIs should be used cautiously in patients who are susceptible to liver damage.
\end{abstract}

Key words: non-small-cell lung cancer; hepatotoxicity; chemotherapy; pemetrexed; tyrosine kinase inhibitor

\section{Introduction}

Chemotherapy is one of the major standard treatment strategies for patients with advanced non-small cell lung cancer (NSCLC) [1]. It improves patient survival, but also produces a variety of toxic side effects among which liver injury is commonly experienced $[2,3]$. The incidence of chemotherapyrelated hepatotoxicity ranges from $12.1 \%$ to $80 \%$ based on different regiments and population [3-5]. While mild hepatic dysfunction usually improves without intervention, some patients experience severe hepatotoxicity that may demand treatment delay or suspension and can result in a worse prognosis. Deteriorated hepatic function may even increase the risk of other systemic side effects because drug metabolism is influenced by liver dysfunction. The so far reported data of chemotherapy-induced hepatotoxicity were mostly based on clinical trials with stringent inclusion criteria and limited sample size. It 
is therefore necessary to investigate broad scale chemotherapy related hepatotoxicity data in the real-world setting.

Hepatotoxicity following chemotherapy mostly attributes to either applied drugs or potential confounding diseases. Platinum-based doublet chemotherapy is the standard first-line regimen for patients with advanced lung cancer. Pemetrexed, docetaxel, gemcitabine, paclitaxel, and vinorelbine have been approved for first-line treatment of NSCLC, of which pemetrexed displays superior effectiveness and has become the preferential drug for lung adenocarcinomas. The rate of pemetrexedrelated all grade hepatotoxicity was strikingly high in previous studies, ranging from 39.3-71\% [6-8]. While the rate of hepatotoxicity caused by single anticancer drugs varies in clinical trials, the development of combination chemotherapy makes the situation more complex. Previous studies on leukemic, breast, and colon cancers have demonstrated that combined chemotherapy increases hepatic toxicity in patients [9-12]. However, we require a better understanding of the specific liver injury details associated with combination treatment in NSCLC, including clinical features, serum enzyme patterns, and differences among regimens.

With respect to preexisting risk factors for hepatotoxicity, viral hepatitis raises an important concern prior to chemotherapy administration. Hepatitis B reactivation was reported in up to $50 \%$ of hepatitis B surface antigen-positive patients who received chemotherapy, leading to hepatic decompensation and sacrifice in 5\% of cases [13]. Younger age at diagnosis, abnormal liver function before chemotherapy, and chronic alcohol consumption are other risk factors for liver injury after chemotherapy [4, 14], and high-risk populations may require prophylaxis or intensive surveillance following chemotherapy.

Our study evaluated the risk factors and regimen related differences of hepatotoxicity during and post first-line doublet chemotherapy in patients with advanced lung adenocarcinomas. We investigated patients who were susceptible to liver dysfunction and the nature of hepatic toxicity across different regimens over time.

\section{Methods}

\section{Patients}

This retrospective study reviewed the medical records of patients with lung adenocarcinoma who were admitted to the hospital between January 2014 and December 2016. To investigate the incidence and risk factors of hepatic dysfunction during first-line chemotherapy and after first-line treatment, we designed a 2-stage study format. Enrolled patients were first included in the analyses of hepatotoxicity during first-line chemotherapy. Eligible patients were consecutively selected with inclusion criteria as follows: age $\geq 18$ years, histologically or cytologically confirmed lung adenocarcinoma with stage IIIB/IV or recurrent disease, chemotherapy naive, receiving first-line double platinum-contained chemotherapy. Patients receiving prior epidermal growth factor receptor-tyrosine kinase inhibitor (EGFR-TKI) before first-line treatment or concurrent TKIs in first-line treatment were excluded from the stage 1 analysis. Totally 2108 patients were studied in the $1^{\text {st }}$ stage analysis. Within this group, regularly followed-up patients who received subsequent post first-line treatment without hepatotoxicity detected during first-line treatment were included in the $2^{\text {nd }}$ stage analyses.

Staging was determined according to the $7^{\text {th }}$ edition of TNM staging system. The dose of carboplatin was calculated by area under the curve and other chemotherapeutic agents were dosed based on body surface area. Clinical characteristics, including age, gender, Eastern Cooperative Oncology Group (ECOG) performance score (PS), stage, smoking status, chronic alcohol consumption history, the presence of pretreatment liver impairment, hepatitis B surface antigen (HBs-Ag) or hepatitis C antibody (HCV-Ab), and liver metastases were recorded for each patient. The primary endpoint of this study was the risk of all-types and all-grades of hepatotoxicity.

\section{Liver function assessment}

A liver function test was performed before and at least biweekly after chemotherapy administration. Parameters including aspartate aminotransferase (AST), alanine aminotransferase (ALT), and total bilirubin (TBL) were examined and results were reported as ULN values. Hepatotoxicity was graded according to the Common Terminology Criteria for Adverse Events (CTCAE), version 4.0.

\section{Statistical analysis}

Baseline characteristics were quantified through applying descriptive statistics. A chi-square or Fisher's exact test was utilized to compare categorical data, as appropriate. The association between variables and hepatic dysfunction during treatment were evaluated using a logistic regression analysis. To eliminate bias introduced by nonrandomized treatment assignments, patients who received first-line pemetrexed or non-pemetrexed doublet chemotherapy were matched 1:1 by the 
nearest-neighbor method. All statistical analyses were performed using SPSS 22.0 software (IBM, Armonk, NY, USA) and R version 3. 2. 2 (Institute for Statistics and Mathematics, Vienna, Austria; www. R-project .org) with $\mathrm{R}$ packages (MatchIt and foreign). A p-value less than 0.05 was considered statistically significant.

Table 1. Patient characteristics.

\begin{tabular}{lll}
\hline Variable & All patients (n=2108) & $\begin{array}{l}\text { Patients in the 2nd stage } \\
\text { analysis }(\mathrm{n}=892)\end{array}$ \\
\hline $\begin{array}{l}\text { Age, median (IQR) } \\
\text { Age }\end{array}$ & $60(53-66)$ & $60(54-65)$ \\
$<65$ years & $1481(70.3)$ & $638(71.5)$ \\
$\geq 65$ years & $627(29.7)$ & $254(28.5)$ \\
Gender & $1157(54.9)$ & $480(53.8)$ \\
Male & $951(45.1)$ & $412(46.2)$ \\
Female & & \\
ECOG PS & $2100(99.6)$ & $886(99.3)$ \\
$0 \sim 1$ & $8(0.4)$ & $6(0.7)$ \\
2 & & $101(11.3)$ \\
Stage & $470(22.3)$ & $587(65.8)$ \\
IIIB & $1370(65.0)$ & $204(22.9)$ \\
IV & $268(12.7)$ & \\
Recurrent & & $799(89.6)$ \\
Pretreatment liver & & $93(10.4)$ \\
impairment & $1891(89.7)$ & \\
No & $217(10.3)$ & $611(68.5)$ \\
Yes & & $281(31.5)$ \\
Smoking status & $1439(68.3)$ & \\
Never & $699(31.7)$ & $854(95.7)$ \\
Ever & & $38(4.3)$ \\
Drinking history & $1996(94.7)$ & $846(94.8)$ \\
No & $112(5.3)$ & $46(5.2)$ \\
Yes & & $818(91.7)$ \\
HBs-Ag or HCV-Ab & $1994(94.6)$ & $74(8.3)$ \\
Absent \\
Present
\end{tabular}

\section{Results}

A total of 2108 patients were included in our analysis. The overall cohort was $54.9 \%$ male, with a median age of 60 years (IQR, 53-66 years). The majority of patients were of PS 0-1. At the time of final analysis, in December 2016, 892 patients receiving subsequent post first-line treatment were included in the second stage of analysis. Patients' clinical characteristics are summarized in Table 1.

\section{Risk factors of liver dysfunction following first-line double platinum chemotherapy}

The predictors of hepatotoxicity were examined in 2108 patients undergoing first-line therapy using logistic regression modeling. After adjusting for potential confounders, increased liver impairment was found to associate with younger age $<65$ years $(\mathrm{OR}, 2.398$ [95\% CI, 1.755-3.275]; $\mathrm{P}<0.001)$, pretreatment liver dysfunction (OR, 2.285 [95\% CI, 1.622-3.220]; $\mathrm{P}<0.001$ ), and pemetrexed-containing regimens (OR, 1.835 [95\% CI, 1.408-2.393]; P < 0.001) (Table 2).

Table 2. Logistic regression analysis for occurrences of liver dysfunction in 2108 patients undergoing first-line double platinum chemotherapy.

\begin{tabular}{|c|c|c|c|c|c|c|}
\hline \multirow[t]{2}{*}{ Variable } & \multirow{2}{*}{\multicolumn{2}{|c|}{$\begin{array}{l}\text { Liver } \\
\text { dysfunction, } \\
\text { No. }\end{array}$}} & \multicolumn{2}{|c|}{ Univariable analysis } & \multicolumn{2}{|l|}{$\begin{array}{l}\text { Multivariable } \\
\text { analysis }\end{array}$} \\
\hline & & & $\begin{array}{l}\text { Odds Ratio } \\
(95 \% \mathrm{CI})\end{array}$ & $\begin{array}{l}\mathrm{P} \\
\text { value }\end{array}$ & $\begin{array}{l}\text { Odds Ratio } \\
(95 \% \mathrm{CI})\end{array}$ & $\begin{array}{l}\mathrm{P} \\
\text { value }\end{array}$ \\
\hline & No & Yes & & & & \\
\hline Age & & & & 0.000 & & 0.000 \\
\hline$\geq 65$ years & 572 & 55 & Reference & & Reference & \\
\hline$<65$ years & 1220 & 261 & $\begin{array}{l}2.225 \\
(1.636-3.025)\end{array}$ & & $\begin{array}{l}2.398 \\
(1.755-3.277)\end{array}$ & \\
\hline Gender & & & & 0.576 & & \\
\hline Male & 979 & 178 & Reference & & & \\
\hline Female & 813 & 138 & $\begin{array}{l}0.934 \\
(0.734-1.188)\end{array}$ & & & \\
\hline Smoking status & & & & 0.667 & & \\
\hline Never & 1220 & 219 & Reference & & & \\
\hline Ever & 572 & 97 & $\begin{array}{l}0.945 \\
(0.729-1.224)\end{array}$ & & & \\
\hline Drinking history & & & & 0.093 & & 0.127 \\
\hline No & 1703 & 293 & Reference & & Reference & \\
\hline Yes & 89 & 23 & $\begin{array}{l}1.502 \\
(0.934-2.415)\end{array}$ & & $\begin{array}{l}1.463 \\
(0.898-2.383)\end{array}$ & \\
\hline $\begin{array}{l}\text { Pretreatment liver } \\
\text { impairment }\end{array}$ & & & & 0.000 & & 0.000 \\
\hline No & 1630 & 261 & Reference & & Reference & \\
\hline Yes & 162 & 55 & $\begin{array}{l}2.120 \\
(1.520-2.957)\end{array}$ & & $\begin{array}{l}2.285 \\
(1.622-3.220)\end{array}$ & \\
\hline HBs-Ag or HCV-Ab & & & & 0.806 & & \\
\hline Absent & 1696 & 298 & Reference & & & \\
\hline Present & 96 & 18 & $\begin{array}{l}1.067 \\
(0.636-1.792)\end{array}$ & & & \\
\hline Liver metastases & & & & 0.329 & & \\
\hline No & 1688 & 302 & Reference & & & \\
\hline Yes & 104 & 14 & $\begin{array}{l}0.752 \\
(0.425-1.332)\end{array}$ & & & \\
\hline Chemotherapy & & & & 0.000 & & 0.000 \\
\hline Non-Pemetrexed & 771 & 92 & Reference & & Reference & \\
\hline Pemetrexed & 1021 & 224 & $\begin{array}{l}1.839 \\
(1.418-2.385)\end{array}$ & & $\begin{array}{l}1.835 \\
(1.408-2.393)\end{array}$ & \\
\hline
\end{tabular}

\section{Comparison of hepatotoxicity frequency and severity between first-line patients with pemetrexed or non-pemetrexed doublet chemotherapy}

Covariate differences between patients with either pemetrexed or non-pemetrexed (Gemcitabine, Vinorelbine, Paclitaxel, Docetaxel) regimens were compared. No significant differences were observed across all variables, with the exception that the pemetrexed regimen was more likely to be combined with carboplatin than the non-pemetrexed regimen. To rule out selection bias between the groups, covariates in the two groups were matched using propensity scores (Table 3 ). 
Table 3. Comparison of variables before and after propensity score matching in patients undergoing first-line double platinum chemotherapy.

\begin{tabular}{|c|c|c|c|c|c|c|}
\hline \multirow[t]{2}{*}{ Variable } & \multicolumn{3}{|c|}{ Before matching } & \multicolumn{3}{|c|}{ After matching } \\
\hline & $\begin{array}{l}\text { Pemetrexe } \\
d(n=1245)\end{array}$ & $\begin{array}{l}\text { Non-peme } \\
\text { trexed } \\
(\mathrm{n}=863)\end{array}$ & $P$ value & $\begin{array}{l}\text { Pemetrexe } \\
\mathrm{d}(\mathrm{n}=844)\end{array}$ & $\begin{array}{l}\text { Non-peme } \\
\text { trexed } \\
(\mathrm{n}=844)\end{array}$ & $P$ value \\
\hline Age & & & 0.1285 & & & $>0.9999$ \\
\hline$<65$ years & $859(69.0)$ & $622(72.1)$ & & $622(73.7)$ & $622(73.7)$ & \\
\hline$\geq 65$ years & $386(31.0)$ & 241 (27.9) & & $222(26.3)$ & $222(26.3)$ & \\
\hline Gender & & & 0.3131 & & & 0.5243 \\
\hline Male & $672(54.0)$ & $485(56.2)$ & & $462(54.7)$ & $475(56.3)$ & \\
\hline Female & $573(46.0)$ & $378(43.8)$ & & $382(45.2)$ & $369(43.7)$ & \\
\hline ECOG PS & & & $>0.9999$ & & & $>0.9999$ \\
\hline $0 \sim 1$ & 1240 (99.6) & $860(99.7)$ & & 841 (99.6) & 841 (99.6) & \\
\hline 2 & $5(0.4)$ & $3(0.3)$ & & $3(0.4)$ & $3(0.4)$ & \\
\hline $\begin{array}{l}\text { Smoking } \\
\text { status }\end{array}$ & & & 0.1792 & & & 0.1753 \\
\hline Never & $864(69.4)$ & $575(66.6)$ & & $586(69.4)$ & $560(66.4)$ & \\
\hline Ever & $381(30.6)$ & $288(33.4)$ & & $258(30.6)$ & $284(33.6)$ & \\
\hline $\begin{array}{l}\text { Drinking } \\
\text { history }\end{array}$ & & & 0.9767 & & & 0.8285 \\
\hline No & 1179 (94.7) & 817 (94.7) & & $800(94.8)$ & $798(94.5)$ & \\
\hline Yes & $66(5.3)$ & $46(5.3)$ & & $44(5.2)$ & $46(5.5)$ & \\
\hline $\begin{array}{l}\text { Pretreatment } \\
\text { liver } \\
\text { impairment }\end{array}$ & & & 0.2965 & & & 0.4789 \\
\hline No & $1124(90.3)$ & 767 (88.9) & & $758(89.8)$ & 749 (88.7) & \\
\hline Yes & $121(9.7)$ & $96(11.1)$ & & $86(10.2)$ & $95(11.3)$ & \\
\hline $\begin{array}{l}\text { HBs-Ag or } \\
\text { HCV-Ab }\end{array}$ & & & 0.9486 & & & $>0.9999$ \\
\hline Absent & 1178 (94.6) & $816(94.6)$ & & 798 (94.5) & $798(94.5)$ & \\
\hline Present & $67(5.4)$ & $47(5.4)$ & & $46(5.5)$ & $46(5.5)$ & \\
\hline $\begin{array}{l}\text { Liver } \\
\text { metastases }\end{array}$ & & & 0.8940 & & & $>0.9999$ \\
\hline No & $1176(94.5)$ & $814(94.3)$ & & 797 (94.4) & 797 (94.4) & \\
\hline Yes & $69(5.5)$ & $49(5.7)$ & & $47(5.6)$ & $47(5.6)$ & \\
\hline Platinum & & & $<0.0001$ & & & $>0.9999$ \\
\hline Cisplatin & 297 (23.9) & $295(34.2)$ & & 276 (32.7) & $276(32.7)$ & \\
\hline Carboplatin & 948 (76.1) & $568(65.8)$ & & $568(67.3)$ & $568(67.3)$ & \\
\hline
\end{tabular}

Table 4. Comparisons of liver dysfunction in different combination chemotherapies in the first-line treatment after matching.

\begin{tabular}{llll}
\hline Characteristic & Patient No. & All grade events (\%) & $\geq 3$ grade events (\%) \\
\hline All & 1688 & $247(14.6)$ & $14(0.8)$ \\
Pemetrexed & 844 & $156(18.5)$ & $9(1.1)$ \\
Non-pemetrexed & 844 & $91(10.8)$ & $5(0.6)$ \\
Gemcitabine & 541 & $64(11.8)$ & $1(0.2)$ \\
Vinorelbine & 167 & $15(9.0)$ & $3(1.8)$ \\
Paclitaxel & 102 & $9(8.8)$ & $0(0)$ \\
Docetaxel & 34 & $3(8.8)$ & $1(2.9)$ \\
\hline
\end{tabular}

Before matching, a total of $316(15.0 \%)$ liver dysfunction events occurred in the first analysis, of which $17(0.8 \%)$ patients were diagnosed with grade 3-4 hepatotoxicity, and after matching, 844 cases in each group were included in the analysis. Liver dysfunction occurred in $247(14.7 \%)$ patients during the first-line treatment, and among these patients, 14 $(0.8 \%)$ were diagnosed with grade 3-4 hepatotoxicity. The incidence of liver dysfunction, across all grades, in patients with pemetrexed regimen was significantly greater than that of patients treated with non-pemetrexed regimens $(\mathrm{P}<0.0001)$. Specifically, the incidence of hepatotoxicity in gemcitabine, vinorelbine, paclitaxel, or docetaxel-containing regimens was $64(11.8 \%), 15(9.0 \%), 9(8.8 \%)$ and 3 $(8.8 \%)$, respectively. However, with regard to hepatotoxicity above grade 3, no significant differences were observed between pemetrexed and non-pemetrexed groups $(\mathrm{P}=0.4220)$ (Table 4$)$.

\section{Risk factors and incidences of liver dysfunction in post first-line treatments}

Among 892 patients who received post first-line treatment, the median age was 60 years (IQR, 54-65 years). There were $147(16.5 \%)$ events of liver dysfunction in this cohort, of which hepatotoxicity grade $\geq 3$ occurred in 11 (1.2\%) patients. Multivariate logistic regression analysis aimed at identifying hepatotoxicity risk factors revealed that younger age (<65 years, OR, 1.699 [95\% CI, 1.081-2.672]; $\mathrm{P}=0.022$ ), pretreatment liver impairment (OR, 2.951 [95\% CI, 1.783-4.885]; $\mathrm{P}<0.001)$, presence of HBsAg or $\mathrm{HCV}-\mathrm{Ab}$ (OR, 2.905 [95\% CI, 1.487-5.675]; $\mathrm{P}=0.002)$, and TKI therapy (OR, 2.621 [95\% CI, 1.809-3.798]; P<0.001) were independent hepatotoxicity risk factors (Table $5)$.

Table 5. Logistic regression analysis of risk factor of hepatotoxicity in 892 patients receiving post first-line double treatment.

\begin{tabular}{|c|c|c|c|c|c|c|}
\hline \multirow[t]{2}{*}{ Variable } & \multicolumn{2}{|c|}{$\begin{array}{l}\text { Liver } \\
\text { dysfunction, No. }\end{array}$} & \multicolumn{2}{|c|}{ Univariable analysis } & \multicolumn{2}{|l|}{$\begin{array}{l}\text { Multivariable } \\
\text { analysis }\end{array}$} \\
\hline & No & Yes & $\begin{array}{l}\text { Odds Ratio } \\
(95 \% \mathrm{CI})\end{array}$ & $\begin{array}{l}\mathrm{P} \\
\text { value }\end{array}$ & $\begin{array}{l}\text { Odds Ratio } \\
(95 \% \mathrm{CI})\end{array}$ & $\begin{array}{l}P \\
\text { value }\end{array}$ \\
\hline Age & & & & 0.006 & & 0.022 \\
\hline$<65$ years & 519 & 119 & $\begin{array}{l}1.851 \\
(1.192-2.874)\end{array}$ & & $\begin{array}{l}1.699 \\
(1.081-2.672)\end{array}$ & \\
\hline$\geq 65$ years & 226 & 28 & Reference & & Reference & \\
\hline Gender & & & & 0.731 & & \\
\hline Male & 399 & 81 & Reference & & & \\
\hline Female & 346 & 66 & $\begin{array}{l}0.940 \\
(0.659-1.341)\end{array}$ & & & \\
\hline Smoking status & & & & 0.601 & & \\
\hline Never & 513 & 98 & Reference & & & \\
\hline Ever & 232 & 49 & $\begin{array}{l}1.106 \\
(0.759-1.611)\end{array}$ & & & \\
\hline Drinking history & & & & 0.742 & & \\
\hline No & 714 & 140 & Reference & & & \\
\hline Yes & 31 & 7 & $\begin{array}{l}1.152 \\
(0.497-2.667)\end{array}$ & & & \\
\hline $\begin{array}{l}\text { Pretreatment liver } \\
\text { impairment }\end{array}$ & & & & 0.000 & & 0.000 \\
\hline No & 682 & 117 & Reference & & Reference & \\
\hline Yes & 63 & 30 & $\begin{array}{l}2.776 \\
(1.723-4.472)\end{array}$ & & $\begin{array}{l}2.951 \\
(1.783-4.885)\end{array}$ & \\
\hline $\begin{array}{l}\text { HBs-Ag or } \\
\mathrm{HCV}-\mathrm{Ab}\end{array}$ & & & & 0.000 & & 0.002 \\
\hline Absent & 716 & 130 & Reference & & Reference & \\
\hline Present & 29 & 17 & $\begin{array}{l}3.229 \\
(1.724-6.045)\end{array}$ & & $\begin{array}{l}2.905 \\
(1.487-5.675)\end{array}$ & \\
\hline Liver metastases & & & & 0.215 & & \\
\hline No & 687 & 131 & Reference & & & \\
\hline Yes & 58 & 16 & $\begin{array}{l}1.447 \\
(0.807-2.595)\end{array}$ & & & \\
\hline TKI therapy & & & & 0.000 & & 0.000 \\
\hline No & 508 & 67 & Reference & & Reference & \\
\hline Yes & 237 & 80 & $\begin{array}{l}2.559 \\
(1.787-3.666)\end{array}$ & & $\begin{array}{l}2.621 \\
(1.809-3.798)\end{array}$ & \\
\hline
\end{tabular}


Hepatotoxicity occurred in $25.2 \%$ (80/317) of patients who currently or previously received TKI therapy and in $11.6 \%(67 / 575)$ of patients who received chemotherapies alone $(\mathrm{P}<0.0001)$. Hepatotoxicity above grade 3 occurred in $6(1.9 \%)$ patients with TKI therapies and $5(0.9 \%)$ patients receiving chemotherapy alone $(\mathrm{P}=0.5326)$.

\section{Discussion}

The liver is particularly vulnerable to drug insults because this organ is where the majority of drug metabolism occurs. Limited but divergent data existed on the overall incidence and pattern of hepatotoxicity in patients with advanced lung adenocarcinomas. Our study demonstrated that up to one sixth of patients with adenocarcinoma developed liver dysfunction during treatment and the hepatotoxicity patterns suggested mostly mild hepatocellular damage. Increased hepatotoxic risk exists in patients with younger age, pretreatment liver impairment, and evidence of viral hepatitis. Different combination regimens possess different abilities to induce liver injury. Pemetrexed containing therapy exhibited a greater potential for hepatotoxicity than non-pemetrexed regimens during first-line treatment, and TKIs were found to increase hepatic toxicity in post first-line treatment.

The incidence of hepatotoxicity in patients with lung cancers varied by cohort. The prevalence of liver dysfunction in first-line and post first-line treatments in our study was $15.0 \%$ and $16.5 \%$, respectively, which were similar to those observed in a previous study of patients with lung cancer who received chemotherapy [4]. However, we did not observe greater hepatotoxic events across treatment lines, which could possibly be explained through the following reasons. First, in the second stage analysis, we did not include patients who developed hepatic injury in the first-line treatment, whose risk of subsequent hepatic injury was predicted to be high, and as such, incidences of second-line hepatotoxicity might be underestimated. Second, therapeutic agent composition was different between the two stages, and divergent toxicity profiles of anticancer drugs may influence the overall incidence of hepatic toxicity. $60 \%$ of patients used pemetrexed as first-line treatment, while most post first-line cases received docetaxel chemotherapy. Moreover, TKIs were applied in approximately one third of patients in the second stage.

The theory that patients with preexisting liver diseases are prone to experience post- chemotherapy liver damage has been confirmed by our study [4, 14], and underlying diseases may include fatty liver disease, alcoholic hepatitis, viral hepatitis, or liver metastasis. We found that regardless of treatment cycles, chemotherapy or TKI therapy, patients with pretreatment liver impairment display a two-fold greater risk of hepatotoxicity. However, in our study, direct positive correlations were not observed between hepatotoxicity and specific conditions, such as alcohol assumption or liver metastases, which implies that the severity of liver injury plays a greater role than underlying conditions, since the liver has a strong compensation ability. Hepatic toxicity risk increased once liver injury, presented by elevated ALT, AST, or TBL levels, occurred prior to the chemotherapy. Previous studies have also revealed that metabolic status is another influencing factor, and high body mass index (BMI) and low high-density lipoprotein cholesterol (HDL-C) predict chemotherapy-related hepatic dysfunction $[3,15]$.

It is noticeable that hepatitis reactivation gains more attention, as this is a well-recognized complication in patients who are infected with the virus and undergo cytotoxic chemotherapy, however $\mathrm{HBV}$ reactivation seems more common than $\mathrm{HCV}$ reactivation [16]. In lung cancer, hepatitis B reactivation was reported in up to $38 \%$ of patients who were hepatitis B surface antigen positive and received chemotherapy [17], which may lead to hepatic decompensation and even death [16]. In our cohort, the prevalence of $\mathrm{HBsAg}$ and hepatitis C antibodies were found to be $5.4 \%$, in agreement with a previous report from a hepatitis prevalent region [4]. Although we did not dynamically monitor the replicative status of hepatitis virions, our results reveal that patients who present HBs-Ag or $\mathrm{HBcAb}$ are more likely to develop hepatotoxicity after multiple chemotherapy exposures. In other words, the potential for hepatotoxicity elevates with prolonged treatment because of increased liver burden. Our observation is in accordance with a previous study on patients with breast cancer, which found that HBV reactivation appeared at a median of 2.5 chemotherapy cycles. Antiviral prophylaxis has proven to benefit patients with cancer who are at risk for HBV reactivation [17].

In the present study, more occurrences of hepatotoxicity were observed through pemetrexedbased chemotherapy than other platinum-doublet regimens. However, in most cases, these hepatic events tended to be mild and reversible. Indeed, previous studies have demonstrated that pemetrexed alone caused a strikingly high incidence of hepatic toxicity. In the phase II trial in chemotherapy-naïve patients with advanced non-small-cell lung cancer, $600 \mathrm{mg} / \mathrm{m}^{2}$ pemetrexed caused asymptomatic hepatotoxicity in $80 \%$ of patients, with elevations of hepatic biochemistry of up to 20 -fold of normal values 
in $14 \%$ of patients [5]. In clinical trials of $500 \mathrm{mg} / \mathrm{m}^{2}$ standard pemetrexed dose, all grades of transaminase elevation were found in 7.9 to $71 \%$ of previously treated patients, which mostly occurred during the first cycle, and 1.9 to $16.7 \%$ of patients presented grade $3 / 4$ hepatotoxicity $[8,18-20]$. Patients who received pemetrexed were more likely to display grade $3 / 4$ hepatic toxicity compared to those under docetaxel [19]. When combination therapies were administered, pemetrexed-based regimens displayed numerically higher incidences of mild grade ALT elevation $[7,21]$, however there were no significant difference in grade 3/4 ALT alterations between pemetrexed and docetaxel doublet regimens [22]. In agreement with previous findings, our study confirmed that pemetrexed-based doublet chemotherapy was associated with more mild hepatotoxicities than other therapies, although we did not observe differences with respect to severe hepatic events.

While the mechanism of liver injury that occurs during pemetrexed application has not been fully elucidated, enzymes involved in folate metabolism maybe the crucial factors. These enzymes exist in both liver and tumor cells, and therefore, pemetrexed may affect liver cells [7]. While modulation of pemetrexed dose intensity and administration schedule allows adequate treatment without adversely affecting transaminase levels [5], a small proportion of patients still require treatment delays, dose adjustments, or discontinuation in the subsequent cycles [7].

Liver dysfunction occurred more frequently during TKI treatment than chemotherapy [23, 24]. Our study demonstrated that approximately one quarter of post first-line patients who took TKIs developed liver injury, which was significantly more than those who underwent chemotherapy alone. However, the rate of hepatotoxicity in this study seemed uncomparable with that reported in other studies, primarily because incidences of TKI-related hepatotoxicities substantially differed among studies and varied from 6 to $62 \%$ for all grade and 0 to $19 \%$ for grades $>3$ [25-30]. The type of TKI and therapy duration may affect the frequency of liver toxicity. Gefitinib displayed a significantly higher frequency of grade $\geq 3$ hepatotoxicity compared with erlotinib or afatinib $[29,31]$. Clinically significant fatal liver failure was also observed in patients receiving TKIs [28, 32], and greater extents of hepatotoxicities were found when observation period endured for more than 14 months [33].

Our findings that neither aging nor gender were risk factors to hepatotoxicity did not support the persistent assumptions that drug-induced hepatotoxicity increased in the older ages and women.
However, this result is partly in line with the previous findings on drug-induced liver injury and there have several possible explanations for this result $[4,34]$. First, in the current study, patients $\geq 65$ years had a more prominent male predominance $(59.5 \%$ vs. $52.9 \%$, $\mathrm{p}=0.0057)$ than the younger patients, which may counteract the effect of aging and gender on hepatotoxicity. Second, the fact that younger age was associated with cytolytic damage while older age was a determinant for cholestatic damage may explain the susceptibility of younger patients in our study because chemotherapy or TKI-induced liver damage were mostly represented as hepatocellular injury. Third, elderly patients tend to have more chemotherapy-associated adverse events such as neutropenia, anemia and thrombocytopenia, which usually cause a suspension or delay of chemotherapy and might affect the incidence of hepatotoxicity.

Our study had several limitations. First, a majority of patients were treated with pemetrexed because of its proven effectiveness in lung adenocarcinoma across previous studies. However, we attempted to include as many patients as possible. Second, due to the retrospective nature of our investigation, potentially critical covariate information might be missing. Third, we did not observe patient outcomes, due to limited follow-up time.

\section{Conclusions}

Patients with advanced lung adenocarcinomas with younger age, pretreatment liver impairment, and viral hepatitis are at risk of hepatotoxicity. Pemetrexed and TKIs should be used with caution, especially in patients at risk of hepatic impairment.

\section{Abbreviations}

EGFR-TKIs: epidermal growth factor receptortyrosine kinase inhibitors; NSCLC: non-small cell lung cancer; PS: performance score; HBs-Ag: hepatitis $\mathrm{B}$ surface antigen; HCV-Ab: hepatitis C antibody; AST: aspartate aminotransferase; ALT: alanine aminotransferase; TBL: total bilirubin.

\section{Acknowledgements}

This study was supported by the National Nature Science Foundation of China (No.: 81502450).

\section{Ethics Committee Approval and Patient Consent}

The study protocol was approved by the Shanghai Chest Hospital Institutional Review Board, and written informed consent was obtained from all study participants. The study was performed in 
accordance with the principles of Declaration of Helsinki.

\section{Competing Interests}

The authors have declared that no competing interest exists.

\section{References}

1. Hanna N, Johnson D, Temin S, et al. Systemic Therapy for Stage IV Non-Small-Cell Lung Cancer: American Society of Clinical Oncology Clinical Practice Guideline Update. J Clin Oncol. 2017; 35:3484-3515.

2. Floyd J, Mirza I, Sachs B, et al. Hepatotoxicity of chemotherapy. Semin Oncol. 2006; 33: 50-67.

3. Lv Y, Ding XS, Li Y, et al. High BMI and low HDL-C predict the chemotherapy-related hepatic dysfunction in Chinese advanced NSCLC patients. Cancer Biomark. 2016; 16: 89-97.

4. Ruofan H, Qiong Z, Xinli Z, et al. Relationships between hepatitis B infection status and liver dysfunction after chemotherapy of lung cancer patients in mainland China. Support Care Cancer. 2013; 21: 1821-6.

5. Clarke SJ, Abratt R, Goedhals L, et al. Phase II trial of pemetrexed disodium (ALIMTA, LY231514) in chemotherapy-naive patients with advanced non-small-cell lung cancer. Ann Oncol. 2002; 13: 737-41.

6. Kubota K, Niho S, Enatsu S, et al. Efficacy differences of pemetrexed by histology in pretreated patients with stage IIIB/IV non-small cell lung cancer: review of results from an open-label randomized phase II study. J Thorac Oncol. 2009; 4: 1530-6.

7. Sakamori Y, Kim YH, Yoshida H, et al. Effect of liver toxicity on clinical outcome of patients with non-small-cell lung cancer treated with pemetrexed. Mol Clin Oncol. 2015; 3: 334-340

8. Smit EF, Mattson K, von Pawel J, et al. ALIMTA (pemetrexed disodium) as second-line treatment of non-small-cell lung cancer: a phase II study. Ann Oncol. 2003; 14: 455-60.

9. Moertel CG, Fleming TR, Macdonald JS, et al. Hepatic toxicity associated with fluorouracil plus levamisole adjuvant therapy. J Clin Oncol. 1993; 11: 2386-90.

10. Harb JM, Werlin SL, Camitta BM, et al. Hepatic ultrastructure in leukemic children treated with methotrexate and 6-mercaptopurine. Am J Pediatr Hematol Oncol. 1983; 5: 323-31.

11. Minow RA, Stern $\mathrm{MH}$, Casey JH. Clinico-pathologic correlation of liver damage in patients treated with 6-mercaptopurine and Adriamycin. Cancer. 1976; 38: 1524-8.

12. Larroquette CA, Hortobagyi GN, Buzdar AU, et al. Subclinical hepatic toxicity during combination chemotherapy for breast cancer. JAMA. 1986; 256: 2988-90.

13. Yeo W, Johnson PJ. Diagnosis, prevention and management of hepatitis B virus reactivation during anticancer therapy. Hepatology. 2006; 43: 209-20.

14. Lu RJ, Zhang Y, Tang FL, et al. Clinical characteristics of drug-induced liver injury and related risk factors. Exp Ther Med. 2016; 12: 2606-2616.

15. Fujiwara $\mathrm{Y}$, Kiura $\mathrm{K}$, Hotta $\mathrm{K}$, et al. Being overweight influences the development of hepatic dysfunction in Japanese patients with non-small-cell lung cancer undergoing cytotoxic chemotherapy. Lung Cancer. 2007; 55: 343-8.

16. Bozza C, Cinausero M, Iacono D, et al. Hepatitis B and cancer: A practical guide for the oncologist. Crit Rev Oncol Hematol. 2016; 98: 137-46.

17. Wu YT, Li X, Liu ZL, et al. Hepatitis B virus reactivation and antiviral prophylaxis during lung cancer chemotherapy: A systematic review and meta-analysis. PLoS One. 2017; 12: e0179680.

18. Ohe Y, Ichinose Y, Nakagawa K, et al. Efficacy and safety of two doses of pemetrexed supplemented with folic acid and vitamin B12 in previously treated patients with non-small cell lung cancer. Clin Cancer Res. 2008; 14: 4206-12.

19. Hanna N, Shepherd FA, Fossella FV, et al. Randomized phase III trial of pemetrexed versus docetaxel in patients with non-small-cell lung cancer previously treated with chemotherapy. J Clin Oncol. 2004; 22: 1589-97.

20. Cohen $\mathrm{MH}$, Johnson JR, Wang YC, et al. FDA drug approval summary: pemetrexed for injection (Alimta) for the treatment of non-small cell lung cancer. Oncologist. 2005; 10: 363-8.

21. Manegold C, Gatzemeier U, von Pawel J, et al. Front-line treatment of advanced non-small-cell lung cancer with MTA (LY231514, pemetrexed disodium, ALIMTA) and cisplatin: a multicenter phase II trial. Ann Oncol. 2000; 11: 435-40.

22. Di BS, Wei KP, Tian JH, et al. Effectiveness and safety of pemetrexed versus docetaxel as a treatment for advanced non-small cell lung cancer: a systematic review and meta-analysis. Asian Pac J Cancer Prev. 2014; 15: 3419-24.

23. Han JY, Park K, Kim SW, et al. First-SIGNAL: first-line single-agent iressa versus gemcitabine and cisplatin trial in never-smokers with adenocarcinoma of the lung. J Clin Oncol. 2012; 30: 1122-8.

24. Teo YL, Ho HK, Chan A, et al. Risk of tyrosine kinase inhibitors-induced hepatotoxicity in cancer patients: a meta-analysis. Cancer Treat Rev. 2013; 39: 199-206.
25. Fukuoka M, Yano S, Giaccone G, et al. Multi-institutional randomized phase II trial of gefitinib for previously treated patients with advanced non-small-cell lung cancer (The IDEAL 1 Trial) [corrected]. J Clin Oncol. 2003; 21: 2237-46.

26. Kris MG, Natale RB, Herbst RS, et al. Efficacy of gefitinib, an inhibitor of the epidermal growth factor receptor tyrosine kinase, in symptomatic patients with non-small cell lung cancer: a randomized trial. JAMA. 2003; 290: 2149-58.

27. Soria JC, Felip E, Cobo M, et al. Afatinib versus erlotinib as second-line treatment of patients with advanced squamous cell carcinoma of the lung (LUX-Lung 8): an open-label randomised controlled phase 3 trial. Lancet Oncol. 2015; 16: 897-907.

28. Park K, Tan EH, O'Byrne K, et al. Afatinib versus gefitinib as first-line treatment of patients with EGFR mutation-positive non-small-cell lung cancer (LUX-Lung 7): a phase 2B, open-label, randomised controlled trial. Lancet Oncol. 2016; 17: 577-89.

29. Ding PN, Lord SJ, Gebski V, et al. Risk of Treatment-Related Toxicities from EGFR Tyrosine Kinase Inhibitors: A Meta-analysis of Clinical Trials of Gefitinib, Erlotinib, and Afatinib in Advanced EGFR-Mutated Non-Small Cell Lung Cancer. J Thorac Oncol. 2017; 12: 633-643.

30. Maemondo M, Minegishi Y, Inoue A, et al. First-line gefitinib in patients aged 75 or older with advanced non-small cell lung cancer harboring epidermal growth factor receptor mutations: NEJ 003 study. J Thorac Oncol. 2012; 7: 1417-22.

31. Takeda M, Okamoto I, Nakagawa K. Pooled safety analysis of EGFR-TKI treatment for EGFR mutation-positive non-small cell lung cancer. Lung Cancer. 2015; 88:74-9.

32. Schacher-Kaufmann S, Pless M. Acute Fatal Liver Toxicity under Erlotinib. Case Rep Oncol. 2010; 3: 182-188.

33. Wang J, Wu Y, Dong M, et al. Observation of hepatotoxicity during long-term gefitinib administration in patients with non-small-cell lung cancer. Anticancer Drugs. 2016; 27: 245-50.

34. Lucena MI, Andrade RJ, Kaplowitz N, et al. Phenotypic characterization of idiosyncratic drug-induced liver injury: the influence of age and sex. Hepatology. 2009; 49: 2001-9. 